\title{
RANCANG BANGUN APLIKASI PENERIMAAN PESERTA DIDIK BARU SEKOLAH SWASTA BERBASIS WEB
}

\author{
Nur Rachmat ${ }^{1}$, Molavi Arman ${ }^{2}$ \\ ${ }^{1}$ Program Studi Teknik Informatika, STMIK Global Informatika MDP, Palembang \\ MDP, Palembang \\ e-mail: *11nur.rachmat@mdp.ac.id, ${ }^{2}$ molavi.arman@mdp.ac.id
}

\begin{abstract}
Abstrak
Berdasarkan Surat Edaran Menteri Pendidikan dan Kebudayaan Nomor 4 Tahun 2020 tentang Pelaksanaan Kebijakan Pendidikan dalam Masa Darurat Penyebaran Coronavirus Disease (Covid-19), sekolah diminta menyiapkan mekanisme Penerimaan Peserta Didik Baru (PPDB) mengikuti protokol kesehatan untuk mencegah penyebaran Covid-19, termasuk mencegah berkumpulnya siswa dan orang tua secara fisik di sekolah. Untuk mendukung pemerintah dalam pencegahan penyebaran Covid-19, maka dirancang suatu aplikasi penerimaan peserta didik baru di Sekolah Swasta secara daring. Melalui aplikasi ini, calon peserta didik dapat melakukan pendaftaran dari rumah tanpa perlu datang ke sekolah. Pada penelitian ini, pengembangan sistem menggunakan model waterfall dan aplikasi yang dibuat menggunakan php framework dengan metode Model, View dan Controller (MVC) serta memanfaatkan protokol Simple Mail Transfer Protocol (SMTP) untuk mengirimkan notifikasi email ke calon peserta didik maupun panitia PPDB.
\end{abstract}

Kata kunci: Penerimaan Peserta Didik Baru; Daring; Waterfall; MVC; SMTP

Based on the letter of Minister of Education and Culture Number 4 of 2020 regarding the Implementation of Education Policy in the Emergency Period of the Spread of Coronavirus Disease (Covid-19), schools are required to prepare a mechanism for Admission of New Students (PPDB) following the health protocol to prevent the spread of Covid-19, including preventing physical gathering of students and parents at school. To support the government in preventing the spread of Covid-19, an online application was designed to admission of new students in senior high school. Through this application, prospective students can register from home without come to school. In this research, the system of development method uses the waterfall model and applications created using the php framework with the Model, View and Controller (MVC) method and the Simple Mail Transfer Protocol (SMTP) protocol to send email notifications to prospective students and PPDB committee.

Keywords: Admission Of New Students; Online; Waterfall;, MVC; SMTP

\section{PENDAHULUAN}

Berkenaan dengan penyebaran Coronavirus Disease (Covid-19) yang semakin meningkat di provinsi Sumatera Selatan, dimana pada akhir bulan Mei 2020 ini jumlah kasus di provinsi Sumatera Selatan sebanyak 982 positif, 6.231 ODP, 567 PDP, 5.597 OTG, 203 sembuh, dan 34 meninggal [1], maka dalam proses
Penerimaan Peserta Didik Baru (PPDB) perlu mempertimbangkan kesehatan calon peserta didik, tenaga pendidik dan tenaga kependidikan di lingkungan sekolah.

Berdasarkan Surat Edaran Menteri Pendidikan dan Kebudayaan Nomor 4 Tahun 2020 tentang Pelaksanaan Kebijakan Pendidikan dalam Masa Darurat Penyebaran Coronavirus Disease (Covid19), sekolah diminta menyiapkan 
mekanisme PPDB mengikuti protokol kesehatan untuk mencegah penyebaran Covid-19, termasuk mencegah berkumpulnya siswa dan orang tua secara fisik di sekolah [2].

Untuk mengatasi masalah tersebut dan mendukung pemerintah dalam pencegahan penyebaran Covid-19, maka diperlukan suatu aplikasi penerimaan peserta didik baru secara daring. Calon peserta didik dapat melakukan pendaftaran dari rumah tanpa perlu datang ke sekolah. Agar dapat diakses dari rumah, aplikasi dibangun berbasis web menggunakan bahasa pemrograman PHP dan database MySQL. Aplikasi ditempatkan di sebuah hosting sehingga dapat diakses darimana saja dan kapan saja sehingga calon peserta didik dan orang tua tidak perlu lagi datang ke sekolah.

Sehubungan dengan hal di atas, maka penulis membuat penelitian yang dapat membatu sekolah dalam melaksanakan proses PPDB. Adapun judul dari penelitian ini yaitu "Rancang Bangun Aplikasi Penerimaan Peserta Didik Baru Sekolah Swasta Berbasis Web".

\section{TINJAUAN PUSTAKA}

\subsection{PPDB}

Penerimaan Peserta Didik Baru (PPDB) merupakan proses penerimaan peserta didik atau siswa SD, SMP, dan SMA. Pada tahun 2020 ini, pelaksanaan Penerimaan Peserta Didik Baru (PPDB) sedikit berbeda dari tahun sebelumnya. Adapun ketentuan PPDB berdasarkan Surat Edaran Menteri Pendidikan dan Kebudayaan Nomor 4 Tahun 2020 tentang Pelaksanaan Kebijakan Pendidikan dalam Masa Darurat Penyebaran Coronavirus Disease (Covid-19) yaitu Dinas Pendidikan dan sekolah diminta menyiapkan mekanisme PPDB yang mengikuti protokol kesehatan untuk mencegah penyebaran Covid-19, termasuk mencegah berkumpulnya siswa dan orangtua secara fisik di sekolah [3].

\subsection{Web}

Web adalah suatu sistem yang berkaitan dengan dokumen yang digunakan sebagai media untuk menampilkan teks, gambar, multimedia baik video maupun audio dan lainnya pada jaringan internet [4].

\subsection{HTML}

HTML atau HyperText Markup Language adalah bahasa markup yang digunakan untuk membuat sebuah halaman web. HTML ini merupakan pondasi dasar dari halaman web. File HTML disimpan dengan ekstensi .html dan dapat diakses melalui web browser [4].

\subsection{CSS}

CSS atau Cascading Style Sheet adalah bahasa yang digunakan untuk memberikan gaya atau style pada halaman web yang tidak bisa dilakukan oleh bahasa markup HTML [4]. Dengan CSS, halaman web menjadi lebih indah dan membuat web menjadi responsif menyesuaikan ukuran layar desktop, tablet dan smartphone.

\subsection{Javascript}

Javascript adalah bahasa pemrograman yang dapat digunakan untuk menangani logika program yang dijalankan pada halaman web. Dengan javascript, halaman web menjadi lebih interaktif [4]. Rilis terbaru dari javascript pada bulan juni 2018 yaitu ECMAScript 2018.

\subsection{PHP}

PHP atau Hypertext Preprocessor adalah bahasa pemrograman yang dapat disisipkan ke dalam HTML. PHP pertama kali dibuat pada tahun 1995 oleh Rasmus Lerdorf. PHP merupakan server-side- 
programming, yaitu bahasa pemrograman yang dijalankan di sisi server [4].

\subsection{Framework PHP}

Framework PHP adalah sebuah kerangka kerja pengembangan aplikasi berbasis PHP yang berisi sejumlah aturan dan fungsi-fungsi umum yang telah dibuat dan dapat digunakan dan diubah sesuai kebutuhan untuk memudahkan pengembangan, meningkatkan performa aplikasi dan mempercepat waktu pembuatan aplikasi [4]. Framework PHP dikembangkan menggunakan metode Model View Controller (MVC).

MVC merupakan sebuah metode yang membagi aplikasi menjadi 3 bagian yaitu Model, View dan Controller [5].

a. Model

Model mewakili struktur data. Bertugas untuk mengambil, menyisipkan dan memperbarui data dalam database berdasarkan instruksi dari Controller.

b. View

Bertugas untuk menyajikan tampilan berupa informasi kepada pengguna berdasarkan instruksi dari Controller.

c. Controller

Sebagai perantara antara Model dan View dan sumber daya lainnya yang diperlukan untuk memproses permintaan HTTP dan menghasilkan halaman web.

Beberapa framework PHP yang banyak digunakan antara lain CakePHP, Codeigniter, Laravel, Symfony, Yii, dan Zend.

\subsection{Codeigniter}

Codeigniter adalah sebuah framewok pengembangan aplikasi atau toolkit untuk membuat sebuah website menggunakan bahasa PHP. Codeigniter ini framework yang kecil, memiliki performa yang baik, sedikit konfigurasi, menggunakan pola MVC dan menyediakan banyak library yang dibutuhkan untuk mempercepat proses pembuatan website. Pada 1 Mei 2020, Codeigniter merilis versi terbaru yaitu Codeigniter v4.0.3 [5].

\subsection{TCPDF}

TCPDF adalah salah satu library PHP gratis yang digunakan untuk membuat laporan PDF. TCPDF dapat membuat laporan PDF menggunakan tag HTML sehingga sangat memudahkan dalam membuat laporan PDF yang berisi teks, tabel gambar, barcode, dan QR-Code [6].

\subsection{SMTP}

SMTP atau Simple Mail Transfer Protocol adalah suatu protokol yang digunakan untuk berkomunikasi antara server untuk mengirimkan email dari server hosting ke server email. Pada Codeigniter sudah tersedia fungsi mail() untuk mengirimkan email, akan tetapi ada server hosting yang menonaktifkan fungsi mail() dan juga proses pengiriman emailnya lambat. Gmail merupakan salah satu layanan email milik Google yang menggunakan SMTP. SMTP Gmail bisa digunakan pada Codeigniter dengan syarat mengaktifkan Less Secure Apps Access pada Gmail terlebih dahulu. Fungsi email pada aplikasi PPDB ini dapat digunakan untuk pengiriman bukti pendaftaran, notifikasi pembayaran yang dilakukan calon peserta didik untuk panitia PPDB, dan notifikasi pembayaran yang sudah diverifikasi oleh panitia PPDB.

\subsection{MySQL}

Database Managemen System (DBMS) adalah aplikasi yang dipakai untuk mengelola basis data. MySQL adalah salah satu DBMS yang banyak digunakan dalam pengembangan aplikasi web [7]. MySQL 
bersifat open source sehingga dapat digunakan untuk keperluan pribadi maupun komersil. MySQL menggunakan perintah Structured Query Language (SQL) yang digunakan untuk Data Definition Language (DDL), dan Data Manipulation Language (DML) [4].

a. Data Definition Language (DDL) DDL digunakan untuk mendefinisikan data di dalam database seperti membuat database dan tabel, menghapus tabel dan database serta mengubah struktur tabel. Beberapa query yang termasuk ke dalam DDL, antara lain CREATE, DROP, ALTER, dan RENAME.

b. Data Manipulation Language (DML)

DML digunakan untuk memasukkan, mengubah dan menghapus data dari database. Beberapa query yang termasuk ke dalam DML, antara lain SELECT, INSERT, UPDATE, dan DELETE.

\subsection{Visual Studio Code}

Visual Studio Code adalah editor yang gratis, ringan tetapi powerful dalam penggunaannya. Visual Studio Code bisa digunakan di Windows, macOS dan Linux. Visual Studio Code memiliki fitur extension, linter (penanda error), intelisense (auto complete), dan terintegrasi dengan git. Pada bulan April 2020, Visual Studio Code mencapai versi 1.45.1 [8].

\subsection{Unified Modeling Language}

Unified Modelling Language atau UML adalah bahasa visual yang digunakan untuk memahami, menjelaskan, membangun dan mendokumentasikan suatu sistem. Untuk menggambarkan suatu sistem digunakan diagram UML. Pada penelitian ini diagram UML yang digunakan antara lain use case diagram, dan activity diagram [9].

\subsection{Penelitian Terdahulu}

Penelitian [10] yaitu Rancang Bangun Sistem Informasi Penerimaan Siswa Baru pada SMK Budhi Warman 1 Jakarta. Berdasarkan hasil penelitian didapatkan sistem informasi penerimaan peserta didik baru berbasis web menggunakan bahasa pemrograman PHP dan basis data MySQL dengan pengujian menggunakan Black Box Testing.

Penelitian [11] yaitu Rancang Bangun Sistem Informasi Penerimaan Siswa Baru pada SMK Negeri 7 Palopo. Berdasarkan hasil penelitian didapatkan sistem informasi penerimaan siswa baru dengan pengujian menggunakan Black Box Testing.

Penelitian [12] yaitu Rancang Bangun Sistem Informasi Penerimaan Peserta Didik Baru Berbasis Web (Studi Kasus: SMP Amaliah Bogor). Berdasarkan hasil penelitian didapatkan sistem informasi penerimaan peserta didik baru menggunakan PHP dan MySQL dengan pengujian menggunakan Black Box Testing.

Penelitian [13] yaitu Penerapan Framework Yii pada Pembangunan Sistem PPDB SMP BPPI Baleendah Kabupaten Bandung. Berdasarkan hasil penelitian didapatkan sebuah sistem berbasis web menggunakan Yii Framework dengan metode Model View Controller (MVC).

\section{METODOLOGI PENELITIAN}

\subsection{Metode Pengembangan Sistem}

Metode pengembangan sistem yang digunakan pada penelitian ini adalah model waterfall. Model waterfall atau model air terjun merupakan salah satu siklus hidup (life cycle) dalam pengembangan sistem secara berurutan dimulai dari analisis kebutuhan, desain sistem, pembuatan kode 
program, pengujian, dan tahap pendukung [14].

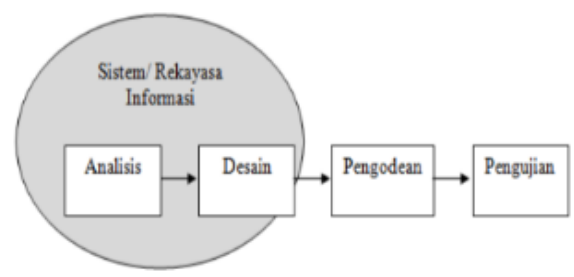

Gambar 1. Metode Waterfall Sumber: [14]

Berikut langkah-langkah metode waterfall sebagai berikut:

a. Analisis Kebutuhan

Pada tahap ini dilakukan proses pengumpulan informasi kebutuhan sistem melalui pengamatan secara langsung atau observasi, diskusi dengan pihak sekolah dan studi pustaka.

Dari hasil pengamatan dan diskusi dengan pihak sekolah, maka dalam proses pembuatan sistem PPDB dibutuhkan perangkat pendukung antara lain:

1. hosting untuk menyimpan aplikasi PPDB,

2. domain untuk memudahkan akses ke aplikasi PPDB,

3. komputer/laptop yang memiliki akses internet untuk panitia PPDB.

Kemudian alur penerimaan peserta didik baru mengalami perubahan dari offline menjadi online yaitu sebagai berikut:

1. calon peserta didik mengakses web PPDB,

2. melakukan registrasi

3. melakukan pembayaran melalui transfer antar bank,

4. mengunggah bukti pembayaran,

5. cetak formulir pendaftaran setelah diverifikasi panitia PPDB.

\section{b. Desain Sistem}

Pada tahap ini dilakukan desain pembuatan sistem untuk memberikan gambaran apa yang akan dibuat seperti struktur data, dan rancangan antarmuka aplikasi.

c. Pembuatan Kode Program

Pada tahap ini dilakukan penulisan kode program menggunakan metode MVC. Pembuatan kode program mengikuti desain sistem yang dibuat pada tahap sebelumnya. d. Pengujian Sistem

Pada tahap ini dilakukan pengujian sistem menggunakan metode pengujian black box untuk mengetahui apakah aplikasi yang dibuat sudah sesuai dengan desain sistem dan memastikan tidak ada lagi kesalahan atau error pada aplikasi.

e. Pendukung atau pemeliharan

Pada tahap ini dilakukan pemeliharaan dari aplikasi yang sudah digunakan. Pemeliharaan dilakukan jika adanya kesalahan yang muncul dan tidak terdeteksi di tahap pengujian.

\subsection{Use Case Diagram}

Use case diagram adalah diagram yang mendeskripsikan fungsi sebuah sistem dari perspektif manusia. Dalam use case diagram terdapat sebuah actor yang berinteraksi dengan sistem [9]. Pada aplikasi ini yang menjadi actor yaitu calon peserta didik dan panitia PPDB.

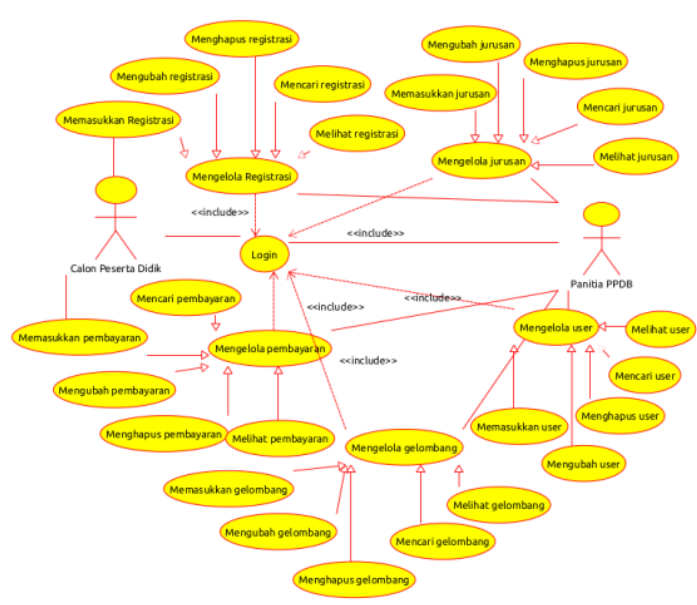

Gambar 2. Use Case Diagram 


\subsection{Activity Diagram}

Activity diagram menggambarkan aliran kerja atau aktivitas pada suatu sistem atau proses bisnis [9].

Tujuan dari pembuatan activity diagram ini agar membantu memahami keseluruhan proses dari Penerimaan Peserta Didik Baru (PPDB) yang melibatkan calon peserta didik dan panitia Penerimaan Peserta Didik Baru (PPDB).

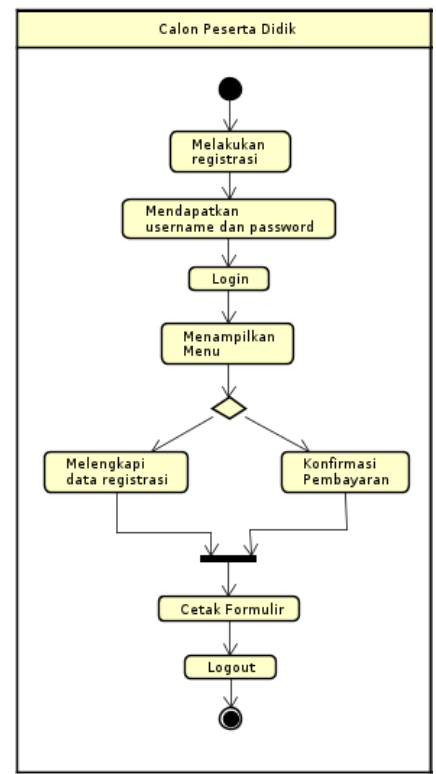

Gambar 3. Activity Diagram Calon Peserta Didik

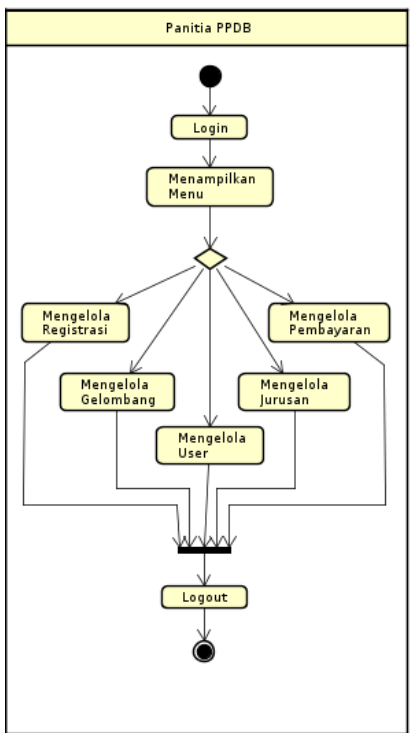

Gambar 4. Activity Diagram Panitia PPDB

\subsection{Entity Relationship Diagram}

Entity Relationship diagram merupakan diagram yang menggambar hubungan antara entitas. Entitas merupakan objek nyata yang diterjemahkan ke dalam database [9].

Pada penelitian ini, semua entitas dalam perancangan ERD memiliki relasi dengan entitas-entitas lain. Entitas users untuk menyimpan data login panitia PPDB, entitas registrasi untuk menyimpan data calon peserta didik, entitas pembayaran untuk menyimpan data pembayaran, entitas gelombang untuk menyimpan data gelombang PPDB dan entitas jurusan untuk menyimpan data jurusan yang ada di SMA Swasta.

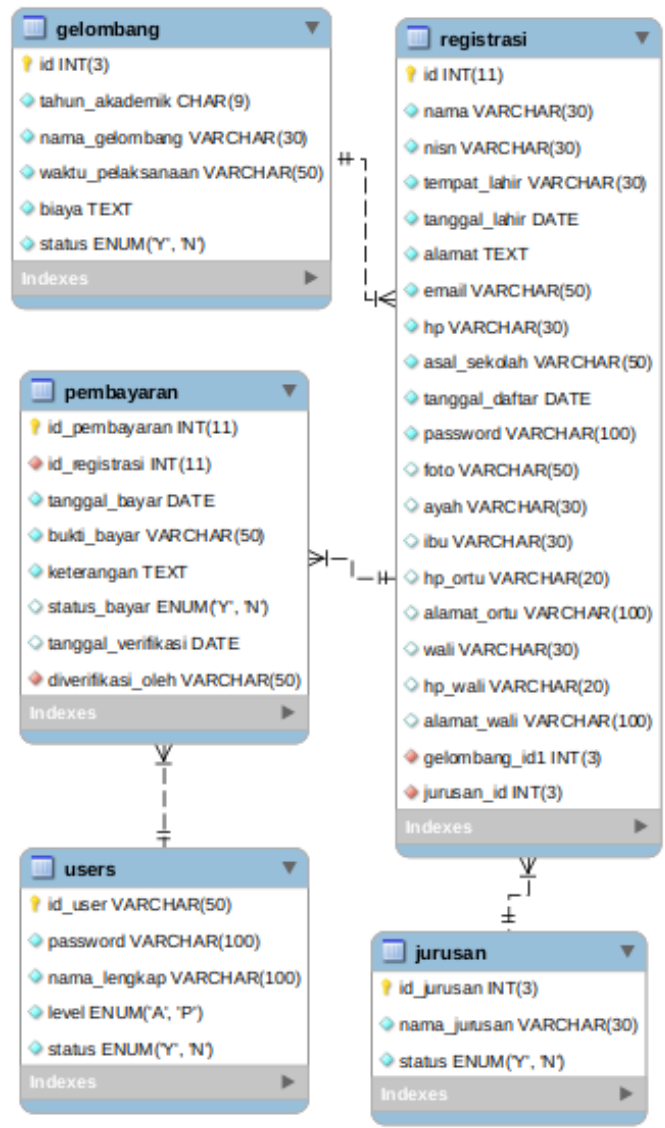

Gambar 5. Entity Relationship Diagram 


\subsection{Rancangan Antarmuka}

Rancangan Antarmuka merupakan tahap yang dilakukan sebelum tahap pengkodean program. Hasil dari rancangan pada tahap ini menjadi acuan dalam pembuatan tampilan aplikasi. Berikut ini rancangan antarmuka aplikasi PPDB Sekolah Swasta antara lain antarmuka halaman registrasi, antarmuka halaman login, antarmuka halaman dashboard calon peserta didik, dan antarmuka halaman dashboard panitia.

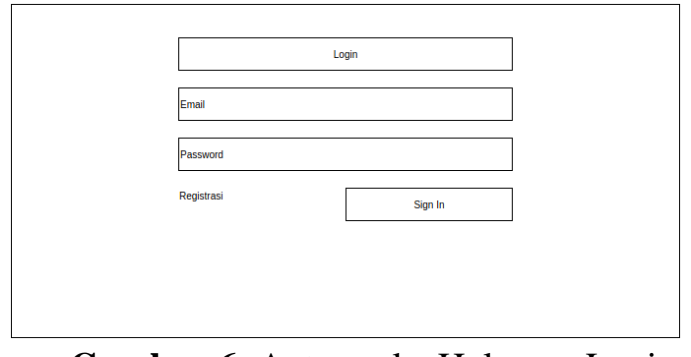

Gambar 6. Antarmuka Halaman Login

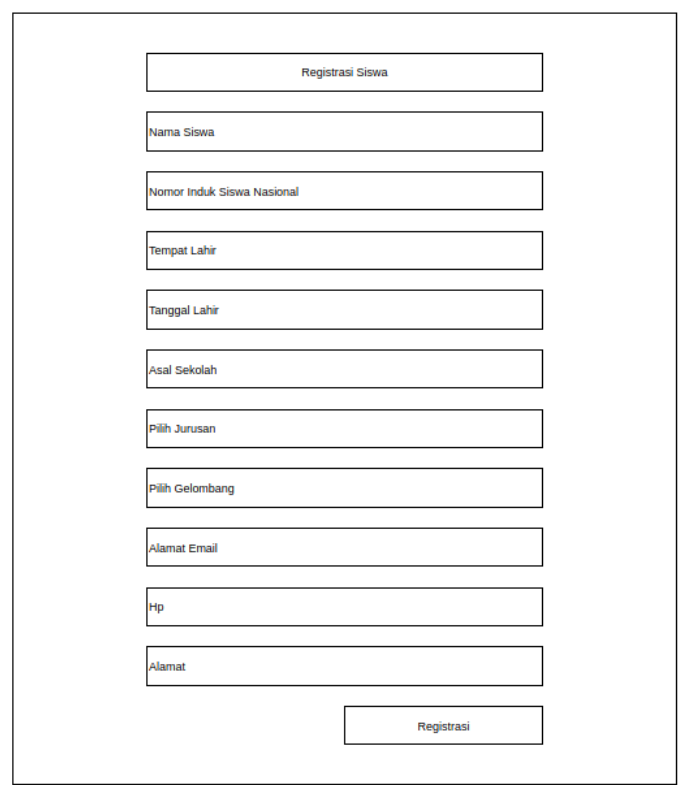

Gambar 7. Antarmuka Halaman Registrasi

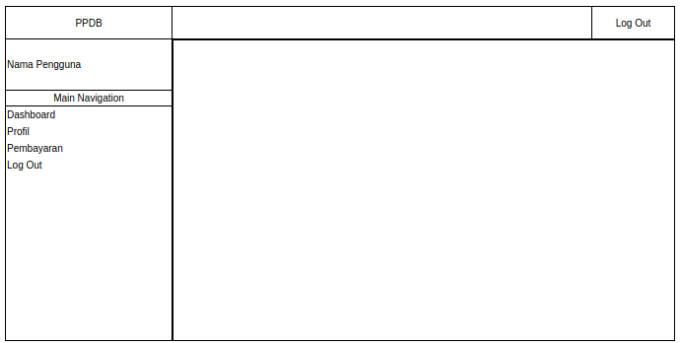

Gambar 8. Antarmuka Halaman

Dashboard Calon Peserta Didik

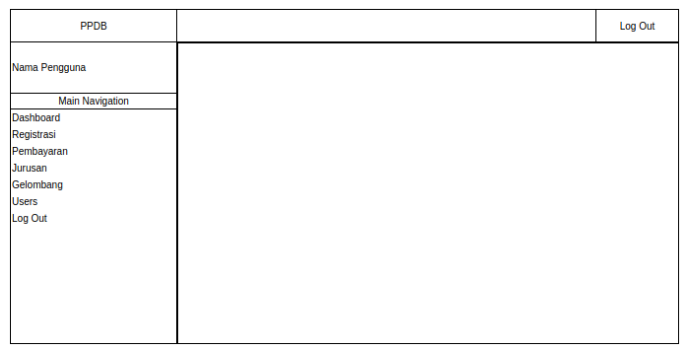

Gambar 9. Antarmuka Halaman Dashboard Panitia PPDB

\section{HASIL DAN PEMBAHASAN \\ 4.1 Hasil Penelitian}

Hasil implementasi dari perancangan dan pengkodean program pada tahap sebelumnya berupa Aplikasi Penerimaan Peserta Didik Baru pada Sekolah Swasta Berbasis Web dengan tampilan sebagai berikut:

\section{Halaman Login}

Halaman yang pertama kali ditampilkan adalah halaman login. Pada halaman ini menampilkan form login siswa dan satu link ke halaman registrasi PPDB.

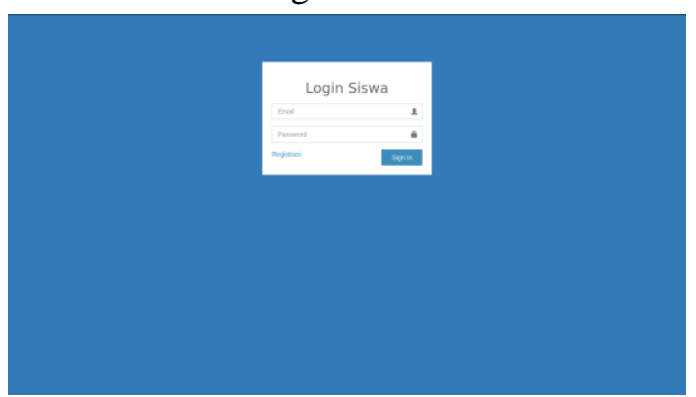

Gambar 10. Halaman Login 


\section{Halaman Registrasi}

Halaman registrasi digunakan calon peserta didik untuk registrasi di Sekolah Swasta. Setelah melakukan registrasi, calon peserta didik akan mendapatkan email notifikasi yang berisi username dan password untuk login ke aplikasi PPDB.

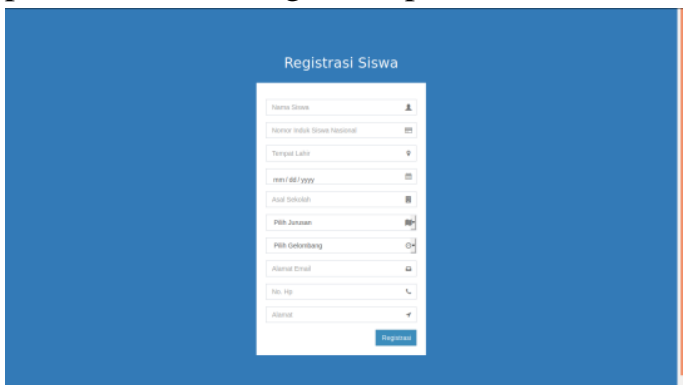

Gambar 11. Halaman Registrasi

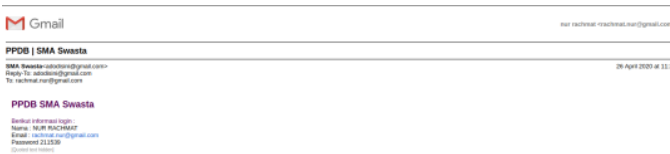

Gambar 12. Notifikasi Email

\section{Halaman Dashboard Calon Peserta Didik}

Setelah melakukan registrasi, calon peserta didik mendapatkan username dan password yang dikirimkan ke email calon peserta didik. Username dan password digunakan untuk login ke dalam aplikasi PPDB. Jika login berhasil akan tampil halaman dashboard.

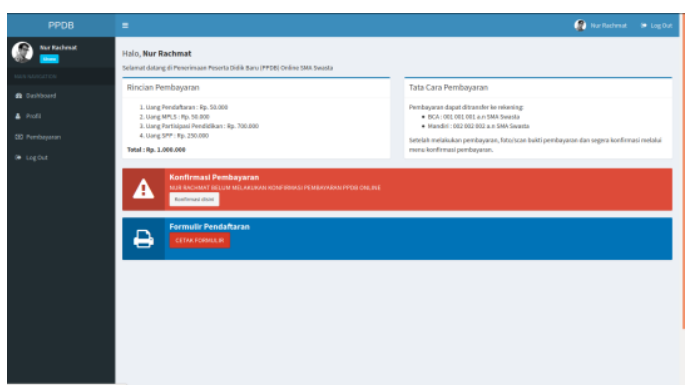

Gambar 13. Halaman Dashboard Calon Peserta Didik
Pada halaman dashboard terdapat menu profil, pembayaran, informasi biaya, tata cara pembayaran dan cetak formulir pendaftaran.

\section{Halaman Profil}

Halaman profil dapat diakses setelah calon peserta didik melakukan login terlebih dahulu. Pada halaman ini, calon peserta didik diminta untuk melengkapi biodata diri.

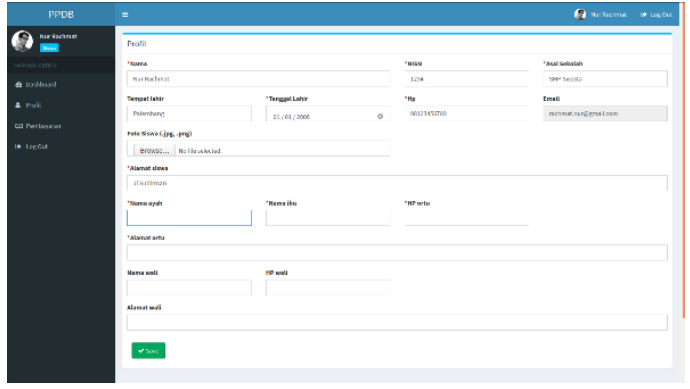

Gambar 14. Halaman Profil Calon Peserta Didik

Setelah calon peserta didik melengkapi biodata dan melakukan konfirmasi pembayaran biaya pendaftaran, maka formulir pendaftaran dapat diunduh dan cetak.

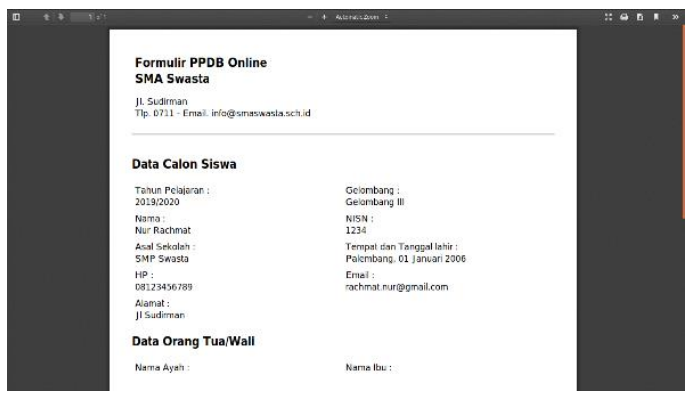

Gambar 15. Cetak Formulir Pendaftaran

\section{Halaman Konfirmasi Pembayaran}

Sama seperti halaman profil, halaman konfirmasi pembayaran dapat diakses setelah melakukan login terlebih dahulu. Pada halaman ini, calon peserta didik dapat mengunggah bukti pembayaran biaya pendaftaran. 


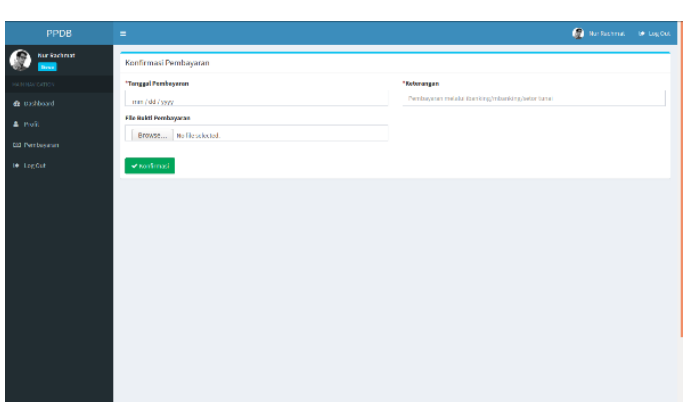

Gambar 16. Halaman Konfirmasi Pembayaran

\section{Halaman Dashboard Panitia PPDB}

Halaman dashboard panitia PPDB dapat diakses setelah panitia PPDB melakukan login terlebih dahulu. Login menggunakan username dan password. Jika username dan password benar akan tampil halaman dasboard.

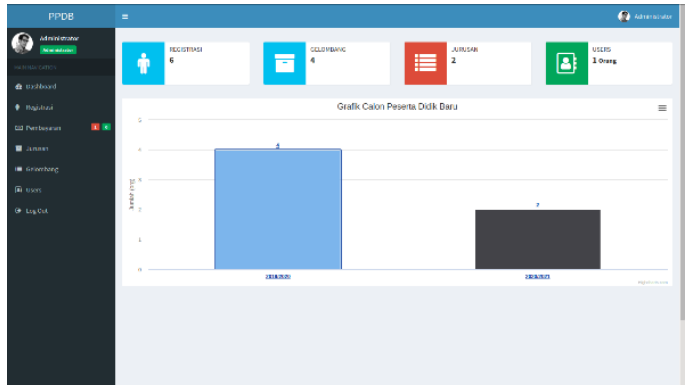

Gambar 17. Halaman Dashboard Panitia PPDB

Pada halaman ini terdapat grafik jumlah calon peserta didik per tahun akademik dan berdasarkan jumlah asal sekolah.

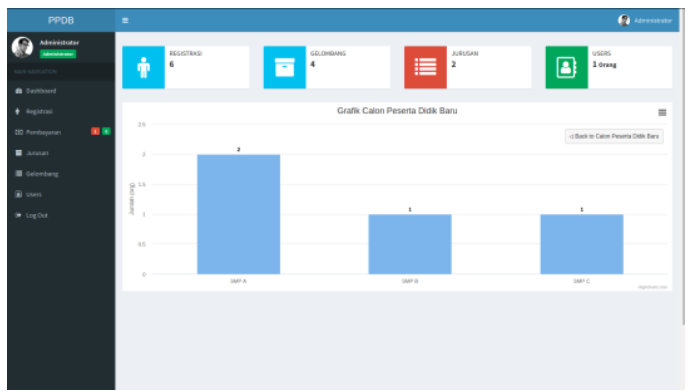

Gambar 18. Grafik Jumlah Calon Peserta Didik

\section{Halaman Data Registrasi}

Halaman data registrasi dapat diakses setelah panitia PPDB melakukan login terlebih dahulu. Halaman ini menampilkan data registrasi calon peserta didik dalam bentuk tabel. Pada halaman ini juga tersedia tombol add untuk menambah data calon peserta didik dan tombol ekspor data registrasi calon peserta didik ke dalam file excel.

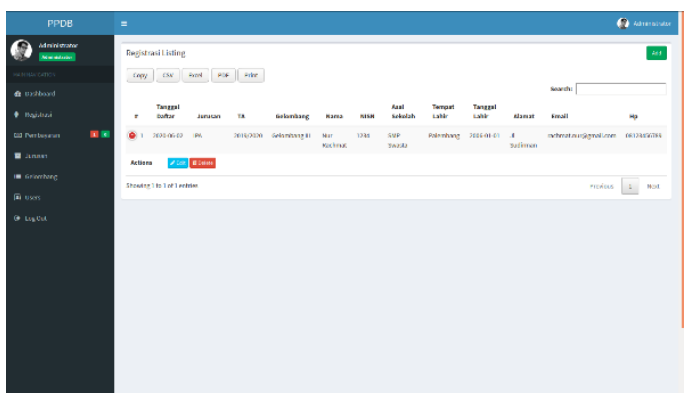

Gambar 19. Halaman Data Registrasi

\section{Halaman Data Pembayaran}

Sama seperti halaman data registrasi, halaman data pembayaran dapat diakses setelah panitia PPDB melakukan login terlebih dahulu. Halaman ini menampilkan data calon peserta didik yang melakukan konfirmasi pembayaran biaya pendaftaran. Pada halaman ini juga terdapat tombol ekspor data pembayaran ke dalam file excel.

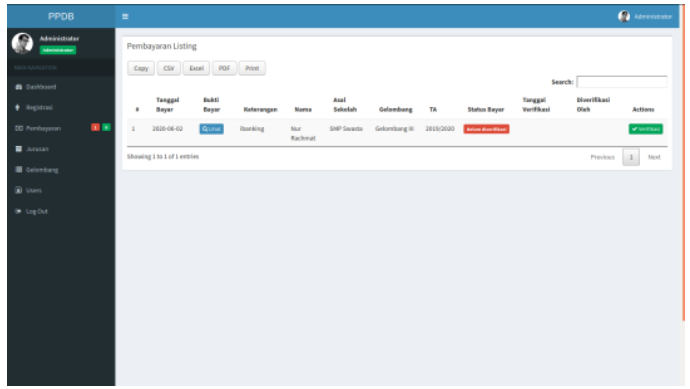

Gambar 20. Halaman Data Pembayaran

\section{Halaman Data Jurusan}

Halaman data jurusan menampilkan data jurusan yang ada di Sekolah Swasta. Panitia PPDB dapat menambah, mengubah dan menghapus data jurusan melalui halaman ini. Data ini dibutuhkan ketika calon peserta didik melakukan registrasi. 


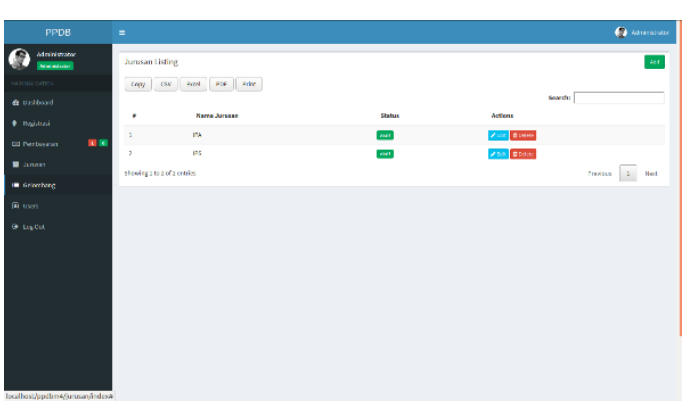

Gambar 21. Halaman Data Jurusan

\section{Halaman Data Gelombang}

Halaman data gelombang menampilkan data tahun akademik, gelombang, waktu pelaksanaan, dan biaya. Panitia dapat menambah, mengubah dan menghapus data gelombang melalui halaman ini. Data ini dibutuhkan ketika calon peserta didik melakukan registrasi.

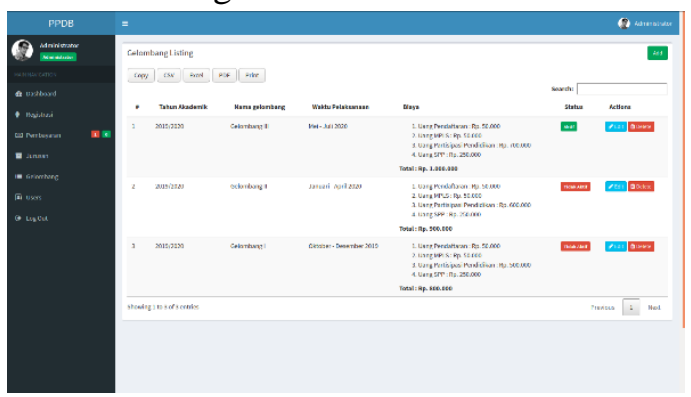

Gambar 22. Halaman Data Gelombang

\section{Halaman Data User}

Halaman data user menampilkan data user panitia PPDB. Pada halaman ini dapat menambah, mengubah dan menghapus data user.

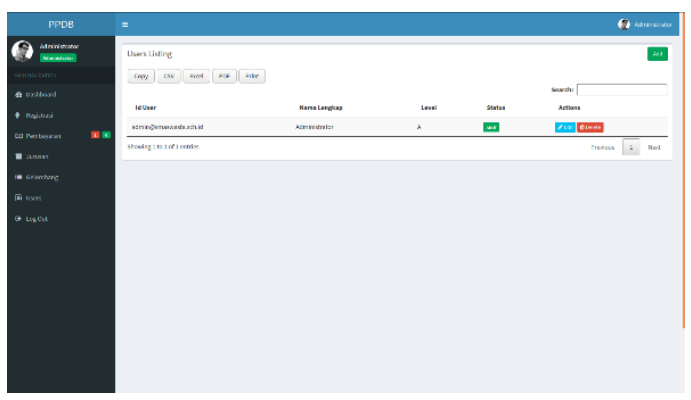

Gambar 23. Halaman Data User

\subsection{Hasil Pengujian Aplikasi}

Pada tahap ini dilakukan pengujian aplikasi menggunakan metode black box.

Tabel 1. Pengujian oleh Calon Peserta Didik

\begin{tabular}{|c|c|c|}
\hline $\begin{array}{l}\text { Antar } \\
\text { Muka }\end{array}$ & Pengujian & Hasil \\
\hline Login & $\begin{array}{l}\text { Memasukkan } \\
\text { username } \\
\text { dan } \\
\text { password }\end{array}$ & $\begin{array}{l}\text { Gagal, } \\
\text { username/password } \\
\text { salah atau belum } \\
\text { terdaftar }\end{array}$ \\
\hline Registrasi & $\begin{array}{l}\text { Mengisi } \\
\text { input } \\
\text { registrasi dan } \\
\text { menekan } \\
\text { tombol } \\
\text { registrasi } \\
\end{array}$ & $\begin{array}{l}\text { Berhasil dan } \\
\text { mendapat } \\
\text { notifikasi email }\end{array}$ \\
\hline Login & $\begin{array}{l}\text { Memasukkan } \\
\text { username } \\
\text { dan } \\
\text { password } \\
\text { yang ada di } \\
\text { notifikasi } \\
\text { email }\end{array}$ & $\begin{array}{l}\text { Berhasil dan tampil } \\
\text { halaman dashboard }\end{array}$ \\
\hline Profil & $\begin{array}{l}\text { Memasukkan } \\
\text { input biodata } \\
\text { calon peserta } \\
\text { didik dan } \\
\text { menekan } \\
\text { tombol } \\
\text { simpan }\end{array}$ & $\begin{array}{l}\text { Berhasil, data } \\
\text { profil disimpan }\end{array}$ \\
\hline $\begin{array}{l}\text { Cetak } \\
\text { Formulir }\end{array}$ & $\begin{array}{l}\text { Menekan } \\
\text { tombol cetak } \\
\text { formulir } \\
\text { sementara } \\
\text { belum } \\
\text { melakukan } \\
\text { pembayaran }\end{array}$ & $\begin{array}{l}\text { Gagal, formulir } \\
\text { pendaftaran tidak } \\
\text { tampil }\end{array}$ \\
\hline Pembayaran & $\begin{array}{l}\text { Memasukkan } \\
\text { input } \\
\text { konfirmasi } \\
\text { pembayaran }\end{array}$ & $\begin{array}{l}\text { Berhasil, data } \\
\text { pembayaran } \\
\text { disimpan dan } \\
\text { panitia } \\
\text { mendapatkan email } \\
\text { notifikasi }\end{array}$ \\
\hline Logout & $\begin{array}{l}\text { Menekan } \\
\text { tombol } \\
\text { Logout }\end{array}$ & $\begin{array}{l}\text { Berhasil, kembali } \\
\text { ke halaman login }\end{array}$ \\
\hline
\end{tabular}


Tabel 2. Skenario Pengujian oleh Panitia PPDB

\begin{tabular}{|c|c|c|}
\hline $\begin{array}{l}\text { Antar } \\
\text { Muka }\end{array}$ & Pengujian & Hasil \\
\hline Login & $\begin{array}{l}\text { Memasukkan } \\
\text { username dan } \\
\text { password }\end{array}$ & $\begin{array}{l}\text { Berhasil dan } \\
\text { tampil halaman } \\
\text { dashboard } \\
\text { panitia }\end{array}$ \\
\hline $\begin{array}{l}\text { Data } \\
\text { Registrasi }\end{array}$ & $\begin{array}{l}\text { Menekan } \\
\text { tombol } \\
\text { tambah }\end{array}$ & $\begin{array}{l}\text { Berhasil dan } \\
\text { tampil halaman } \\
\text { tambah data } \\
\text { registrasi }\end{array}$ \\
\hline $\begin{array}{l}\text { Data } \\
\text { Registrasi }\end{array}$ & $\begin{array}{l}\text { Melakukan } \\
\text { pencarian } \\
\text { pada datatable }\end{array}$ & $\begin{array}{l}\text { Berhasil dan } \\
\text { tampil data } \\
\text { registrasi } \\
\text { berdasarkan } \\
\text { keyword } \\
\text { pencarian }\end{array}$ \\
\hline $\begin{array}{l}\text { Data } \\
\text { Registrasi }\end{array}$ & $\begin{array}{l}\text { Menekan } \\
\text { tombol xls }\end{array}$ & $\begin{array}{l}\text { Berhasil dan file } \\
\text { data registrasi } \\
\text { berhasil } \\
\text { diekspor ke } \\
\text { dalam file excel }\end{array}$ \\
\hline $\begin{array}{l}\text { Data } \\
\text { Pembayaran }\end{array}$ & $\begin{array}{l}\text { Menekan } \\
\text { tombol } \\
\text { verifikasi }\end{array}$ & $\begin{array}{l}\text { Berhasil dan } \\
\text { mengirimkan } \\
\text { notifikasi } \\
\text { pembayaran } \\
\text { diterima ke } \\
\text { calon peserta } \\
\text { didik }\end{array}$ \\
\hline $\begin{array}{l}\text { Data } \\
\text { Pembayaran }\end{array}$ & $\begin{array}{l}\text { Menekan } \\
\text { tombol xls }\end{array}$ & $\begin{array}{l}\text { Berhasil dan } \\
\text { data berhasil } \\
\text { diekspor ke } \\
\text { dalam file excel }\end{array}$ \\
\hline $\begin{array}{l}\text { Data } \\
\text { Pembayaran }\end{array}$ & $\begin{array}{l}\text { Melakukan } \\
\text { pencarian } \\
\text { pada datatable }\end{array}$ & $\begin{array}{l}\text { Berhasil dan } \\
\text { tampil data } \\
\text { pembayaran } \\
\text { berdasarkan } \\
\text { keyword } \\
\text { pencarian }\end{array}$ \\
\hline Jurusan & $\begin{array}{l}\text { Input data } \\
\text { jurusan }\end{array}$ & $\begin{array}{l}\text { Berhasil dan } \\
\text { data disimpan }\end{array}$ \\
\hline Gelombang & $\begin{array}{l}\text { Input data } \\
\text { gelombang }\end{array}$ & $\begin{array}{l}\text { Berhasil dan } \\
\text { data disimpan }\end{array}$ \\
\hline User & $\begin{array}{l}\text { Input data } \\
\text { user }\end{array}$ & $\begin{array}{l}\text { Berhasil dan } \\
\text { data disimpan }\end{array}$ \\
\hline Logout & $\begin{array}{l}\text { Menekan } \\
\text { tombol } \\
\text { Logout }\end{array}$ & $\begin{array}{l}\text { Berhasil, } \\
\text { kembali ke } \\
\text { halaman login } \\
\text { panitia }\end{array}$ \\
\hline
\end{tabular}

\section{KESIMPULAN}

Dari hasil rancang bangun aplikasi penerimaan peserta didik baru (PPDB) Sekolah Swasta, dapat disimpulkan bahwa calon peserta didik dapat melakukan registrasi melalui web tanpa perlu datang langsung ke sekolah. Sehingga proses PPDB secara online ini dapat mencegah penyebaran Covid-19 sekaligus menjalankan Surat Edaran Menteri Pendidikan dan Kebudayaan Nomor 4 Tahun 2020 tentang Pelaksanaan Kebijakan Pendidikan dalam Masa Darurat Penyebaran Coronavirus Disease (Covid19). Melalui aplikasi ini juga, Panitia PPDB dapat melihat calon peserta didik yang melakukan registrasi dan dapat melihat data jumlah calon peserta didik yang melakukan registrasi per tahun akademik dan berdasarkan asal sekolah baik dalam angka maupun grafik. Dari data ini, panitia PPDB dapat melakukan evaluasi dan mempersiapkan strategi promosi untuk PPDB berikutnya.

\section{SARAN}

Saran yang dapat diberikan untuk pengembangan aplikasi PPDB Sekolah Swasta berikutnya adalah proses pembayaran terhubung langsung dengan bank atau payment gateway sehingga calon peserta didik tidak perlu melakukan konfirmasi secara manual. Saran berikutnya menggunakan whatsapp center untuk mengirimkan notifikasi dan promosi.

\section{DAFTAR PUSTAKA}

[1] P. P. Sumatera Selatan, "Situasi Terkini Perkembangan Corona Virus Disease-19 (Covid-19) di Provinsi Sumatera Selatan Tanggal 31 Mei 2020," pp. 1-9, 2020.

[2] R. I. Kementerian Pendidikan dan Kebudayaan, "Surat Edaran Nomor 4 Tahun 2020 Tentang Pelaksanaan Kebijakan Pendidikan Dalam Masa Darurat Penyebaran Coronavirus 
Disease (COVID-19)," pp. 1-3, 2020.

[3] R. I. Kementerian Pendidikan dan Kebudayaan, "Surat Edaran Nomor 4 Tahun 2020 Tentang Pelaksanaan Kebijakan Pendidikan Dalam Masa Darurat Penyebaran Coronavirus Disease (COVID-19)," pp. 1-3, 2020.

[4] A. F. . Sibero, Web Programming Power Pack. Yogyakarta: MediaKom, 2013.

[5] B. C. I. of Technology, "Codeigniter," Codeigniter, 2015. [Online]. Available: https://www.codeigniter.com. [Accessed: 01-May-2020].

[6] N. Asuni, "Docs TCPDF." [Online]. Available: https://tcpdf.org/docs/.

[7] P. Hidayatullah and J. K. Kawistara, Pemrograman Web. 2017.

[8] Microsoft, "Visual Studio Code," 2018. [Online]. Available: https://code.visualstudio.com/docs. [Accessed: 01-May-2020].

[9] N. Rachmat, "Perancangan dan Implementasi Aplikasi Pengambilan dan Pemanggilan Antrian SAMSAT Berbasis Web," J. Ilm. Komputasi, vol. 17, no. 2, 2018.

[10] R. Amin, "Rancang Bangun Sistem Informasi Penerimaan Siswa Baru Pada SMK Budhi Warman 1 Jakarta," J. Ilmu Pengetah. dan Teknol. Komput., vol. 2, no. 2, pp. 113-121, 2017.

[11] R. Nasser, S. Saputra, and U. Syarif, "Rancang Bangun Sistem Informasi Penerimaan Siswa Baru pada SMK Negeri 7 Palopo," Pros. Semant. 2017, pp. 224-235, 2017.

[12] E. Irfiani and M. Encep, "Rancang Bangun Sistem Informasi Penerimaan Peserta Didik Baru Berbasis Web (Studi Kasus: Smp Amaliah Bogor)," Swabumi, vol. 5, no. 1, pp. 10-16, 2017.

[13] J. S. Pasaribu, "Penerapan Framework YII pada Pembangunan Sistem PPDB SMP BPPI Baleendah Kabupaten Bandung," J. Ilm. Teknol. Terap., vol. 3, no. 2, pp. 154-163, 2017.
[14] R. Ariani Sukamto and M. Shalahudin, Rekayasa Perangkat Lunak: Terstruktur dan Berorientasi Objek. Bandung: Informatika, 2016. 